\title{
La información y la autonomía como ejes rectores del desarrollo comunal indígena
}

\author{
César Augusto Ramírez Velázquez*
}

Artículo recibido:

27 de junio de 2019

Artículo aceptado:

17 de octubre de 2019

Artículo de investigación

\section{Resumen}

En el presente artículo se utiliza el método exploratorio mediante el cual se analiza el papel de la información a través de los recursos y fuentes que la contienen, y el proceso de autonomía tanto legal como por reconocimiento generado por diversas comunidades indígenas; se hace un primer acercamiento a la vinculación entre ambos aspectos con el fin de constatar si dicha integración repercute en el desarrollo de los pueblos originarios. La conclusión es que, de acuerdo con la información recabada, prefieren la autonomía por respeto y reconocimiento social frente a la obtenida por la vía legal, además, existe una falta de correspondencia del Estado hacia las autoridades indígenas, lo que refleja un distanciamiento diplomático y cordial al tratar

* Instituto de Investigaciones Bibliotecológicas y de la Información, UNAM, México carv@unam.mx

INVESTIGACIÓN BIBLIOTECOLÓGICA, vol. 34, núm. 83, abril/junio, 2020, México, ISSN: 2448-8321 pp. 71-84 
asuntos concernientes a la comunidad; por último, es imprescindible que intercambien información de toda índole con el fin de lograr una convivencia más fructífera y provechosa para ambas partes y principalmente para las comunidades originarias.

Palabras clave: Información; Autonomía Comunitaria; Comunalidad Indígena; Comunidades Originarias

Information and autonomy as guiding axes for indigenous community development

César Augusto Ramírez Velázquez

\begin{abstract}
This paper uses the exploratory method for analyzing the role of information through the sources and resources which it contains it, as well as the autonomy process, both the legal as well as the generated by the diverse indigenous communities. A first approach of the linking between both aspects is made, in order to verify whether such integration impacts in the development of indigenous peoples. The conclusion is that according to the information gathered, they prefer the autonomy due to the respect and social recognition instead of that obtained by legal track. Besides there exists a lack of correspondence by part of the State towards indigenous authorities, which reflects a diplomatic and cordial gap, when treating matters concerning to the community. Lastly, it is an essential condition to interchange information of all kinds in order to achieve a fruitful and rewarding coexistence for both parts, mainly for the native peoples.
\end{abstract}

Keywords: Information; Community Autonomy; Indigenous Communality; Original Communities 


\section{INTRODUCCIÓN}

Toda actividad, proceso y pensamiento ejecutado por el ser humano requiere de una serie de datos que al conjuntarse sistemáticamente proveen cierta información cuyo análisis le ayudará en la obtención de conocimiento para gestionar el trabajo que pretende realizar. Con base en lo anterior, en este trabajo se hace un acercamiento a la importancia que tienen tanto la información como los recursos y fuentes que la contienen para apoyar el proceso de autonomía de las comunidades originarias.

De igual manera se reflexiona sobre el valor que tiene la información para obtener la autonomía legal (concedida por el Estado), lo que supone que la importancia brindada a la información para conseguir la autonomía legítima reconocida por las propias comunidades derivará en el impacto que tendrá en su desarrollo social, cultural y político.

\section{LA INFORMACIÓN Y SUS FUENTES}

Ríos (2018: 230) indica que la información "va del objeto material y su representación en un conjunto de datos hasta incorporarlos a un contexto cognoscitivo o comprensión humana, e incluso, la transformación del entorno"; la información es naturalmente expuesta, por lo cual debe aprenderse socialmente a través de redes compartidas. Asimismo, de acuerdo con Olivé (2012: 137), "necesita ser recuperada e interpretada".

Vista desde los recursos y fuentes que la contienen y siguiendo el pensamiento de Olivé (2012: 148), "no constituye conocimiento, pero puede contribuir a que ciertas representaciones del mundo constituyan conocimiento y, en muchas ocasiones, determinada información es necesaria para que ciertos conocimientos sean posibles". Brinda asimismo una serie de experiencias que abonan en el planeamiento de estrategias, la elaboración adecuada de documentos, la previsión de los tiempos requeridos para cada trámite, el conocimiento de las diversas instituciones y entidades participantes en el proceso, los recursos humanos y económicos que se necesitan para dar a entender a la comunidad en qué consiste el cambio y lograr el empoderamiento de la autonomía y del régimen basado en usos y costumbres.

Por otro lado, de acuerdo a la información requerida, se deben tener presentes a las personas sabias de la comunidad, que a partir del conocimiento de la cultura propia y de sus saberes ancestrales sobre principios que han heredado por generaciones en temas tales como medicina tradicional, organización social, salud, seguridad, ecología, alimentación, vivienda, educación, 
cosmovisión, música y folclore, compartirán dichos conocimientos para sustentar el logro de los objetivos que se planteen en las tareas y actividades encaminadas a la consecución de un nuevo régimen exento de discrepancias políticas que impidan la cohesión comunal y su progreso económico y social.

Asimismo, es pertinente considerar la participación y el apoyo de profesionales especialistas en diversas áreas, independientemente de que sean de las propias comunidades o externos a las mismas, pero que comulguen con la emancipación del sistema gubernamental, el abatimiento de la pobreza y el rezago social en el que viven. Las áreas en las que se requiere su experiencia son, entre otras, derecho indígena, derechos humanos, políticas públicas, salud y seguridad social, cultura, identidad, participación ciudadana, estatal y federal, medio ambiente y recursos naturales, desarrollo y asistencia social.

Dichas personas tienen, además, información sobre prácticas en otras comunidades sobre las mismas temáticas, problemas encontrados, documentos generados, reuniones realizadas en la comunidad, enfrentamientos, rechazo e incomprensión de los gobiernos en turno y apoyo de organismos nacionales e internacionales, así como de organizaciones no gubernamentales.

Los recursos de información como elementos imprescindibles en los procesos de autonomía deben ser evaluados de acuerdo a ciertos criterios que permitan reconocer su validez y confianza. Por lo anterior, se considera pertinente mostrar algunos aspectos a valorar que presenta la Universidad de Alicante, España, tales "como el tipo de fuente de información y su procedencia, su cobertura temporal y geográfica, su actualización, su originalidad, su rigor y exhaustividad, su objetividad, su estructura y su inteligibilidad, su finalidad y el tipo de público al que va dirigida, la cantidad de información que proporciona, etc." (Universidad de Alicante, 2015: 4).

De igual forma, es conveniente establecer una serie de criterios que apoyarán la validez de la información recuperada; en este aspecto, la Universidad de Alicante (2015: 5) indica ocho de ellos vinculados a la calidad del contenido:

- Autoridad de la persona, la editorial o de la organización sobre el tema. El autor responsable de una obra es uno de los principales indicadores de calidad de un trabajo científico. Se valora su conocimiento y experiencia previa del tema, su currículo, su grado de especialización y su prestigio. En el caso de obras colectivas hay que considerar que $[$ sic $]$ funciones desempeña en la misma (dirección, colaboración, coordinación, revisión).

- Actualidad de la información, puede ser relevante en los ámbitos científicos en que está [sic] envejece rápidamente. En otros ámbitos, donde es importante la perspectiva histórica, una menor actualidad puede resultar enriquecedora. 
- Objetivo de la publicación y audiencia a la que va dirigida: documento de carácter científico, profesional o divulgativo, y tipo de público al que se destinan los contenidos, que determinará su nivel de complejidad y exhaustividad.

- Objetividad, precisión y exactitud, que determinan la validez, el grado de confianza ante la fiabilidad de la información. Ha de ser imparcial, completa, distinguir los hechos de las opiniones y verificable, a partir de la bibliografía y las fuentes estadísticas y documentales.

- Originalidad, exhaustividad y cobertura: es importante determinar el nivel de profundidad con que se cubre el tema, qué aspectos trata y su nivel de detalle, si se pueden detectar omisiones importantes; así como si aporta información novedosa o se basa en otros trabajos.

- Organización y estructuración de la información: Si se expone la información de forma clara, estructurada y coherente con su finalidad y su audiencia; con una buena distribución en apartados o capítulos, incluyendo resumen, introducción, metodología y conclusiones.

- Calidad de la expresión y de las ilustraciones, tablas, mapas y gráficos: Si está bien escrita, con corrección gramatical y ortográfica, y si los elementos gráficos y estadísticos adicionales son adecuados y complementan y clarifican al texto.

- Adecuación a las necesidades de información del usuario: la información ha de tener calidad y ser fiable, pero lo más importante es que nos resulte útil.

De lo anterior se desprende que los recursos de información, independientemente del soporte en el que se encuentren (papel, microfilm, electrónico, digital, entre otros) y del tipo de documento que se trate (libro, capítulo, revista, artículo, memoria, ponencia, carta, ensayo, video y grabación sonora, por mencionar algunos), deben contener información adecuada, específica, actualizada, verídica, puntual y necesaria.

Esta información debe constituir un soporte fundamental para las comunidades originarias en el transcurso y quehacer de la obtención, permanencia y preservación de sus sistemas de gobiernos autónomos.

\section{LA AUTONOMÍA DE LAS COMUNIDADES INDÍGENAS}

Hablar de autonomía de las comunidades originarias es expresar una serie de características, elementos y factores que tiene cada una de ellas, hasta el proceso histórico que les ha llevado a instituirse como entidades independientes. Entre las características que se pueden distinguir, de acuerdo a Iturralde (2012: 27 ), se encuentran los 
usos y costumbres [...] constituidos por el sistema de relaciones legales, socio-culturales y políticas, producto de la historia, cosmovisión y aspiraciones de los pueblos y comunidades indígenas en los ámbitos del ejercicio de su autoridad, gobierno y representación política. Incluyen las normas, principios, autoridades y procedimientos a través de los cuales estos sujetos colectivos ejercen su jurisdicción en su ámbito territorial.

Esta aseveración vincula la mayor parte de los aspectos que hacen de las comunidades grupos únicos integrados e independientes, regidos por sus propios criterios de composición social; no obstante, se debe considerar que los usos y costumbres no son necesariamente los mismos para cada comunidad, es decir, en algunas el sistema de gobierno se basa en cargos político-religiosos, en otras se han separado los cargos en civiles y religiosos.

Otra característica se relaciona con las formas de organización del gobierno, en donde, de acuerdo con la sección o área en la que se ubiquen los individuos, tendrán responsabilidades y autoridad en cuanto a las actividades y acciones a realizar, atendiendo e informando a la comunidad mediante las asambleas comunitarias por sectores o en la asamblea general.

En este punto es importante mencionar la presencia vital del Concejo de Ancianos que normalmente es la autoridad principal, o en su defecto el Concejo Mayor o el Concejo de Principales dependiendo de cada comunidad.

En relación con la participación de los miembros de la comunidad en los cargos de gobierno, existen dos formas comunes: sin remuneración durante el tiempo que dure en funciones o en su defecto con un pago simbólico siempre y cuando la comunidad tenga los recursos para tal fin. Las personas nombradas para dichos cargos son elegidas por votación en las asambleas generales.

Comenta Velasco Cruz (2003: 133) que en México, desde la década de los setenta, se percibe un movimiento en el que los indígenas "persiguen dos metas básicas: la dotación de tierras y la defensa de los valores culturales étnicos". En los ochenta, las demandas aumentan; Velasco Cruz concuerda con Pérez Correa (1999: 234-235) y menciona que la población indígena reclama:

- El derecho de preservar o aprovechar sus bosques, sus pastizales, sus minas, sus ríos o sus lagos.

- Garantías para desarrollar su producción agropecuaria y eliminar intermediarios y agiotistas.

- Servicios educativos bilingües e interculturales, así como medidas para preservar su patrimonio y herencia cultural prehispánica.

- Espacios políticos en los congresos estatales y federal, y participación en el diseño y ejecución de sus proyectos de desarrollo. 
- Respeto a los derechos humanos y reclamo de justicia contra masacres, asesinatos y despojos de tierras provocadas por las relaciones de fuerte tensión con los terratenientes y con los gobiernos estatal o federal. (Velasco Cruz, 2003: 133-134)

Sin embargo, a principios de los noventa, el movimiento indígena logra una definición de autonomía operativa basándose en los términos del Convenio 169 "Convenio sobre pueblos indígenas y tribales en países independientes" de la Organización Internacional del Trabajo (OIT), que consistía en tomarla como una posibilidad para ejercer el derecho de autodeterminación de los pueblos indígenas; al mismo tiempo, se manejaba una posible aplicación práctica de la autonomía, basada en una propuesta de autonomía regional pluriétnica como alternativa de carácter nacional-territorial que planteaba la necesidad de crear un cuarto nivel en la división federal de México, que se ubicaría entre el municipio y la entidad federativa, ajustándose además a contextos geográficos donde conviven poblaciones indígenas de diversos orígenes étnicos.

Por otra parte, en Colombia, Osorio Pérez y Barrera Jurado (2013: 253) indican que:

Las demandas autonómicas responden a estas tres dimensiones de la injusticia social. La exclusión de beneficios, recursos, oportunidades y decisiones no solo se deriva de una visión de la sociedad mayor de esos otros como marginales, sino que se acompaña fuertemente de una visión de que esos otros son incapaces, ineptos e inútiles, no solo para aportar a la sociedad en general, sino también para decidir sobre sus propios destinos. Esa mirada peyorativa no escapa a quienes la sufren y, por ello, la propuesta de autonomía configura una vía que los sitúa como actores sociales y políticos. Exigencias de redistribución, de reconocimiento y de participación tanto en el marco estatal como en el extraestatal se conjugan para animar la construcción de procesos autonómicos.

De acuerdo con lo mencionado anteriormente, se considera a la autonomía como un recurso para demostrar a la sociedad circundante que cada comunidad es digna y merecedora de regir su propio destino, demostrando capacidad de planeación, organización y participación de forma independiente, libre y soberana. En su defecto, como lo indican Dinerstein et al. (2013: 33), la autonomía es:

[...] un proceso de construcción en marcha hacia la apertura de espacios territoriales y simbólicos -como la selva, el asentamiento, el núcleo barrial, la ciudaddesde donde se critica la "realidad" capitalista y se anticipan o afirman a través de la experiencia concreta y la reflexión colectivas, nuevas formas existenciales, organizacionales, sociales, relacionales y políticas todavía inexistentes o existentes pero oprimidas y olvidadas. 
Del mismo modo, Diez (2012: 176) refiere que

las autonomías indígenas no son modelos establecidos, sino que las distintas propuestas y sus experiencias concretas se han nutrido de múltiples antecedentes históricos, al tiempo que han ido constituyéndose y modificándose a lo largo de los años. Entonces, más que hablar de autonomía, conviene referirse al proceso de construcción de autonomía o proceso autonómico, enfatizando su carácter dinámico.

Ejemplo claro de esta visión y perspectiva comentan (y coinciden) Osorio Pérez y Barrera Jurado (2013: 247), en cuanto a que "campesinos de muy diversos lugares han mostrado su capacidad para construir espacios de autonomía organizativa y productiva [...] (Vega, 2002; Varela Mora y Romero Picón, 2007)". En consecuencia, la autonomía es el elemento que incita a las comunidades originarias a establecerse como sociedades independientes que buscan la transformación de sus condiciones económicas, sociales y culturales en beneficio de los individuos que las integran, haciendo énfasis en la concepción y práctica de sus tradiciones y costumbres, aunado a la conservación y preservación de su cultura originaria.

\section{VINCULACIÓN DE LA INFORMACIÓN Y LA AUTONOMÍA EN EL DESARROLLO COMUNAL}

Como se ha mencionado en los apartados anteriores, la información va muy de la mano con el proceso de obtención de autonomía, es decir, que cuando las comunalidades ${ }^{1}$ originarias piensan en el mejoramiento de sus condiciones de vida a partir de la búsqueda y obtención de su independencia tutelar por parte del Estado, o cuando conciben mantener su autonomía tradicional lograda a partir del reconocimiento de las comunidades que las circundan, deben tener en cuenta las diversas acepciones que presenta, cuál sería la mejor estrategia para lograrla (en los casos en que buscan su legalización) y de qué forma consolidar su reconocimiento ante el Estado (en los casos en que han sido tradicionalmente autónomas).

1 Iturralde (2012: 26) comenta que "el líder, ideólogo y antropólogo mixe Floriberto Díaz [...] distingue [...] la dimensión fenoménica-visible y la esencial-inmanente de la comunidad, acuñando un nuevo concepto para esta última que bautizó con el nombre de «comunalidad». Los principios que lo definen son lo comunal, la colectividad, la complementariedad y la integralidad, mientras que se compone de los siguientes cinco elementos: la especial relación con la Tierra, el consenso en Asamblea, el servicio gratuito y el trabajo colectivo en beneficio de la comunidad y, por último, los ritos y ceremonias como expresión del don comunal". 
De igual modo, es preciso contar con las capacidades necesarias para buscar, obtener, organizar, analizar y utilizar en diversos momentos y para diferentes temáticas la información que se requiere en cuatro tiempos distintos:

1. Planeación. Obtener la información que apoye el establecimiento de los fundamentos históricos (cultura, usos y costumbres), políticos, jurídicos y legales (derechos indígenas) que motivan la solicitud de autonomía ante las instancias correspondientes tanto del Estado como de otros organismos internacionales y qué aspectos abarcará dicha autonomía, es decir, territorial (comunitaria o regional), por usos y costumbres, política, étnica, económica, entre otras.

2. Proceso. Contar con información referente a las instancias del Estado ante las cuales se va a interponer la solicitud y en su caso formalizar por medio de un pedimento algún otro recurso legal inherente a la obtención de la autonomía.

3. Sistema de gobierno autónomo. Integrar y organizar los documentos con la información generada a lo largo de la causa (desde la solicitud hasta el documento oficial de obtención de la autonomía), con el fin de dar a conocer (difundir y divulgar) a los miembros de las comunidades y al público en general el logro alcanzado. Al interior de las comunidades la difusión podría realizarse mediante asambleas generales, en donde también se atenderá la formalización del régimen autónomo, la estructura planeada y las personas que lo integrarán a través de los procesos que considere pertinentes la comunalidad. En cuanto al público en general (personas externas a la comunidad), se difundirá la información a través de los diversos medios de comunicación (radios comunitarias, periódicos, televisión y en línea a través de redes sociales).

4. Desarrollo comunal. Una vez cumplido el objetivo de consumación legal de la autonomía, se debe instrumentar un lugar (biblioteca y archivo) en donde converjan y se organicen todos los documentos relacionados así como la información generada antes y en el transcurso, más la información que se empiece a crear en la implementación del nuevo sistema de gobierno y en el desarrollo de la comunidad, con el fin de conservarlos y preservarlos para que sean parte primordial de la planificación de estrategias de mejora, programas de apoyo y sustentabilidad comunitaria (social, cultural y política). 
La obtención de la autonomía legal no ha sido fácil para las pocas comunalidades que la han logrado actualmente, ni tampoco ha sido fácil integrar el régimen autónomo de gobierno en su vida cotidiana. Por otra parte, el hecho de sentirse independientes de un sistema gubernamental, que a pesar de todo sigue sin reconocer a muchas comunalidades que se han autoproclamado autónomas, les ha dado motivos para continuar su lucha por lograr que se les respete como grupos dinámicos, prósperos, con ideas claras sobre su futuro y permanencia hegemónica en la vida cultural de las sociedades que las rodean.

Al integrar la información en los aspectos cruciales de la autonomía, y ésta a su vez en la vida de las comunalidades, se derivan una serie de beneficios como los que a continuación se enlistan:

- La implantación y reconocimiento de sistemas de gobierno autónomos creados por la propia comunalidad,

- El respeto y reconocimiento legal de su autonomía y libre determinación por parte del Estado,

- La planeación y organización de sistemas de seguridad establecidos por las propias comunalidades,

- La cohesión al interior de las mismas entre los individuos que las conforman,

- Generación de una mayor relación y más estrecha con otras comunalidades,

- La práctica de la distribución de tareas y actividades en favor de la colectividad, a partir de sistemas de gobiernos libres,

- El manejo organizado y protección de sus recursos naturales,

- La distribución equitativa de los productos generados a través de empresas comunitarias de autogestión,

- La protección de los derechos humanos de las personas integrantes de las comunalidades, $\mathrm{y}$

- El resguardo, preservación y desarrollo de las distintas formas de expresión cultural, social y política.

Como muestra clara de una comunidad que ha logrado con esfuerzo y sacrificios un sistema de gobierno autónomo por usos y costumbres que va en camino de la consolidación, se encuentra la comunidad purépecha de Cherán en el estado de Michoacán, en México. En su momento los cheranenses tuvieron que defender su territorio y los recursos naturales de su municipio, que estaban en peligro ante la violencia de grupos armados que operaban en el estado. Solicitaron el apoyo del gobierno estatal y no lo obtuvieron, por lo 
que el pueblo decidió actuar por su cuenta el 15 de abril de 2011 para evitar el saqueo de sus bosques y por su propia seguridad.

Al amainar la situación problemática, la comunidad decidió exigir y solicitar por la vía legal su autonomía, para reivindicar su derecho a autogobernarse, por el reconocimiento de sus derechos colectivos y en contra de la democracia delegativa del sistema de partidos políticos que no han sido representativos de los intereses de la población. Es así que después de acudir al Instituto Electoral de Michoacán (IEM), quien declaró que carecía de atribuciones para resolver sobre la celebración de elecciones bajo el principio de usos y costumbres (Ventura Patiño, 2012: 166), los cheranenses promovieron un juicio para la protección de sus derechos político-electorales ante el Tribunal Electoral del Poder de la Federación (TRIFE), con el respaldo de 2312 firmas de comuneros de los cuatro barrios (Ventura Patiño, 2012: 166).

El 2 de noviembre de 2012 dicha dependencia emitió su resolución revocando el acuerdo del Consejo General del IEM, relativo a la organización de las elecciones bajo el régimen del sistema de partidos políticos. Tal decisión fue respaldada por la mayoría de los magistrados con voto en favor del proyecto de resolución propuesto por el magistrado presidente del TRIFE (Ventura Patiño, 2012: 166).

Ventura Patiño (2012: 170) al respecto indica que

hay tres puntos que nos interesa destacar de la experiencia de Cherán. Uno, su capacidad organizativa para hacer frente y defenderse ante la embestida del crimen organizado, que por sí solo, sin exagerar, es único en el país. Dos, su capacidad de recurrir al derecho como estrategia política y jurídica para hacer respetar su derecho a elegir a sus autoridades por usos y costumbres, el cual es reconocido en el derecho internacional, lo que sienta un precedente legal para otras comunidades en el país. Tres, su capacidad de estructurar una forma de gobierno comunal que cuenta con el reconocimiento legal y con legitimidad, que cimienta las bases para el buen inicio del gobierno comunal; un reto será mantener esta representatividad.

Debido a lo anterior, son varias las comunidades en distintas regiones del país y de Latinoamérica que han logrado consumar su carácter autónomo ya sea por la vía del respeto y reconocimiento social y las menos por la vía legal, siendo un ejemplo a seguir para los diversos grupos étnicos, a pesar de los problemas y vicisitudes que han tenido que sortear ante gobiernos, cacicazgos, dictadores y grupos antisociales que los menosprecian y los quieren tener bajo su poder de manera ignominiosa. 


\section{Conclusiones}

Un sinnúmero de comunalidades ha optado por no ejercer su derecho a solicitar la autonomía legal, de acuerdo a la información que han obtenido de otras comunidades y su libre determinación; el reconocimiento que para ellas es más importante es el social, es decir, tienen la convicción de dicha afirmación debido a la práctica constante de sus usos y costumbres desde su propia legitimidad, perspectiva organizacional y de buen gobierno.

Una situación recurrente a la que se han enfrentado las comunalidades es la de la falta de reconocimiento de las autoridades indígenas por parte del Estado, lo que impide una relación diplomática y cordial entre ambas partes en los asuntos concernientes a la entrega de recursos, habilitación de programas (sociales, educativos, culturales y de salud, por mencionar algunos), derechos indígenas, desarrollo, participación e implementación de proyectos sustentables (empresariales, industriales, cooperativos, artesanales) o que tengan que ver con los recursos renovables y no renovables de la entidad (eólicos, mineros, combustibles, madereros, acuíferos, entre otros).

Por lo anterior, es imprescindible que el Estado y las comunidades intercambien información de toda índole en dichos aspectos con el fin de lograr una convivencia más fructífera y provechosa para ambas partes, principalmente para las comunalidades indígenas dueñas por derecho adquirido con todas sus prerrogativas jurídicas de los recursos naturales inmersos en sus entidades geográficas.

Los recursos y fuentes de información, en su carácter de proveedores de datos y conocimiento, proporcionan una serie de factores que sustentan a la autonomía como un derecho inalienable de las comunalidades originarias. Al integrar el binomio información-autonomía al quehacer cotidiano de dichas comunidades, se genera un parteaguas en su crecimiento como grupo comunitario que ejerce sus derechos de acuerdo a sus propios usos y costumbres, a su idiosincrasia y a su cosmovisión.

La información y la autonomía son dos aspectos que conllevan a las comunalidades a ejercer un pleno derecho que las independice del Estado, lo cual les permitirá desenvolverse en todos los aspectos en que consideren pertinente avanzar, con el fin de preservar un legado floreciente para las futuras generaciones en torno a lo social, cultural y político.

La experiencia acumulada a lo largo de los años en las comunidades originarias que han logrado ser autónomas por reconocimiento o de manera legal permitirá, a partir del aprovechamiento del binomio información-autonomía, que otras comunidades que aún no han iniciado dicho proceso o que se encuentren en el seguimiento de las diversas etapas o en vísperas de la 
resolución del mismo puedan hacerlo con menos errores, en un tiempo más reducido, con más información, con mayor conocimiento de los procesos autonómicos y con mayor certidumbre de alcanzar un objetivo que les proporcionará mejores oportunidades de bienestar y progreso.

\section{REFERENCIAS}

Diez, J. 2012. “Algunos desafíos de los procesos de construcción de autonomía en el movimiento zapatista”, en Sociabilidades emergentes y movilizaciones sociales en América Latina, coordinado por Armando Chaguaceda y Cassio Brancaleone, 173-195. Buenos Aires: CLACSO.

http://bibliotecavirtual.clacso.org.ar/clacso/gt/20120911032416/Sociabilidadesemergentes.pdf

Dinerstein, A., D. Contartese, M. Deldicque, J. P. Ferrero, L. Ghiotto y R. Pascual. 2013. Movimientos sociales y autonomía colectiva: la política de la esperanza en América Latina. Buenos Aires: Capital intelectual.

https://problemasrurales.files.wordpress.com/2008/12/movimientos_sociales_y_autonomia-dinerstein-2013.pdf

Gasparello, G. y J. Quintana Guerrero, coords. 2010. Otras geografías: experiencias de autonomías indígenas en México. México: Redez, tejiendo la utopía.

Iturralde, I. 2012. Autonomía comunitaria y caciquismo: identidad étnica, control social y violencia en una comunidad mixe de Oaxaca. ICIP Working Papers 2012/2. Barcelona: Institut Català Internacional per la Pau. http://www.observatori.org/paises/pais_68/documentos/WEB\%20WP\%20 2012-2\%20CAST.pdf

Olivé, L. 2012. “Tecnología y cultura”, en Ciencia, tecnología y sociedad, editado por Eduard Aibar y Miguel Angel Quintana, 137-162. Madrid: Trotta, Consejo Superior de Investigaciones Científicas.

Osorio Pérez, F. E. y G. S. Barrera Jurado. 2013. "Por los caminos de la autonomía comunitaria: debates y experiencias desde la autonomía artesanal Kamsá”. Tabula Rasa: revista de bumanidades 19 (jul.-dic.), 245-265.

http://www.revistatabularasa.org/numero19/por-los-caminos-de-la-autonomia-comunitaria-debates-y-experiencias-desde-la-autonomia-artesanal-kamsa/

Pérez Correa, F. 1999. "Marco jurídico para la convivencia pluricultural y multiétnica en el estado mexicano contemporáneo", en La identidad nacional mexicana como problema político y cultural, editado por Raúl Béjar y Héctor Rosales, 225-239. México: Siglo XXI.

Ríos Ortega, J. 2018. "La información como cultura y la contribución bibliotecológica”, en Fortalecimiento, organización y preservación de la información indígena originaria, vol. 1, coordinado por César Augusto Ramírez Velázquez y Hugo Alberto Figueroa Alcántara, 225-256. México: UNAM, IIBI, FFyL.

Universidad de Alicante. 2015. Cómo evaluar la información encontrada. Biblioteca, Material formativo. https://rua.ua.es/dspace/bitstream/10045/46567/1/ci2_avanzado_2014-15_Como-evaluar-informacion.pdf 
Varela Mora, L. e Y. Romero Picón. 2007. Surcando amaneceres: historia de los agrarios de Sumapaz y Oriente del Tolima. Bogotá: Universidad Antonio Nariño, Alcaldía de Sumapaz, Fondo Editorial UAN.

Vega, R. 2002. Gente muy rebelde. Protesta y modernización en Colombia II. Indígenas, campesinos y protestas agrarias. Bogotá: Pensamiento crítico.

Velasco Cruz, S. 2003. El movimiento indígena y la autonomía en México. México: UNAM, UPN.

http://www.posgrado.unam.mx/publicaciones/ant_col-posg/23_Mov_indigena.pdf

Ventura Patiño, M. del C. 2012. "Proceso de autonomía en Cherán: Movilizar el derecho”. Espiral (Guadalajara) XIX (55): 157-176.

https://www.redalyc.org/articulo.oa?id=13826109006

Para citar este texto:

Ramírez Velázquez, César Augusto. 2020. "La información y la autonomía como ejes rectores del desarrollo comunal indígena”. Investigación Bibliotecológica: archivonomía, bibliotecología e información 34 (83): 71-84.

http://dx.doi.org/10.22201/iibi.24488321xe.2020.83.58141 